\title{
Study on the Quality Evaluation of Old Block Renewal from the Perspective of Healthy City
}

\author{
Yanzhu Ding, Chongqing University, CHINA \\ LI Yang, Chongqing University, CHINA \\ Qianting Chen, Chongqing University, CHINA
}

$\mathrm{Na} \mathrm{Li,} \mathrm{General} \mathrm{Office} \mathrm{of} \mathrm{the} \mathrm{Party} \mathrm{committee} \mathrm{of} \mathrm{Yili} \mathrm{Prefecture,} \mathrm{Xinjiang,} \mathrm{CHINA}$

\begin{abstract}
Under the background of China's new urbanization, urban construction has entered the stock renewal stage, and the research on the renewal of old blocks is urgent. Taking the block material environment and residents' living needs as the research object, this paper puts forward a set of evaluation system and design method for block renewal at macro and meso levels. By analyzing the connotation of the concept of healthy city and the governance characteristics of old blocks, and based on the theory of healthy social determinants, health promotion theory and meta theory of healthy city, a six-dimensional evaluation index system of "healthy blocks" based on "healthy built environment - healthy people's body and mind" is established. Taking Xichang street block in Changsha as an example, the renewal quality of old blocks is evaluated, Adjust and optimize the update strategy. The research results have certain reference significance in evaluating urban public health problems, evaluating the built environment of current blocks, investigating residents' health psychological needs, and optimizing the renewal methods of urban old blocks, which provides a new exploration path and technical support for the quality improvement construction of old blocks in healthy cities in China.
\end{abstract}

\section{Keywords}

Healthy cities, old blocks, urban renewal

\section{Introduction}

Old urban areas are usually found in the city center or surrounding spaces. Among them, part of the old city due to the historical building elements, certain historical and cultural value and urban development memory make it become " a certain representative of urban traditional blocks", received wide attention, was included in the official scope of legal protection[1][2][3][4]. In the meantime, another part of the old urban areas are not classified within the scope of protection because of "insufficient historical value", "poor status quo", "single function" and other reasons. Therefore, it failed to get the local government, commercial investment and other effective attention. So that the optimization and reconstruction of some old urban areas floating on the surface, it is always difficult to reach the fundamental problems of development and construction.For these "ordinary" old urban areas without development, deeply into the main contradiction, understand the residents' opinions and suggestions to improve the living environment, and putting forward the targeted renewal method and effective applications on the basis of status quo analysis has become a top priority.

The upgrading and transformation of old urban areas is an important part of urban renewal. Scholars in China and abroad mainly conduct research from the following three aspects: First, the study of the 
concept of transformation. With the people-oriented planning concept deeply rooted in the hearts of the people, the transformation of the old urban areas has gradually shifted from paying attention to physical structure, building facade and other physical elements to meeting the special functional needs shown by demographic characteristics in the old urban areas [5][6][7].Other scholars have injected the concept of green transformation into the old urban renewal project, which not only provides a better living environment for the living people, but also effectively carries out energy conservation and emission reduction work in cities[8][9][10].Second, the study of the form of the main body.According to the different composition of the participants, the transformation model of the old urban areas can be divided into the top-down mode of government guidance, the market-oriented transformation model composed of enterprises and social organizations, and the model of community organic renewal[11][12].Third, the work development mechanism and its efficiency research.Combined with the practical problems of land use distribution income, discuss the relationship between the interests of the old urban areas and the contradiction in the imbalance[13]; or relying on the optimization model, discuss the mechanism and means of investment groups to participate in the upgrading and reconstruction project of the old urban area[14].

To sum up, scholars' research on the upgrading and transformation of the old urban areas has been gradually deepened, which provides theoretical and practical guidance for this article.However, in the face of many practical problems in the upgrading and reconstruction of old urban areas in China, there are still some deficiencies in the existing research.The sudden novel coronavirus emergency once again broke people's peaceful life, seriously endangered people's lives, and once again sounded the alarm call to urban development and safety and health.How to establish the values of "people-oriented" and "life first", following the natural development laws and basic principles of urban life organisms and building a truly ecological, healthy, safe and beautiful city are worth our profound reflection[15]. The perspective analysis object of existing research in the old city transformation, focus more on the historical significance of block or area, and more from the perspective of public power, orthodox theory "regularity" of the old city renewal problem, focusing on the research and analysis of the old city environment,the historical evolution of the old city and its development mechanism research is less. Under the requirements of fine, high quality development, the transformation of the old city needs to go deep into smaller units in response to some special community crowd demand and development model of custom requirements, the existing "block system" concept is effectively illustrates the necessity of small unit space governance. Block contains urban diversity and rich neighborhood relationship which is destroyed in demolition and excessive development, therefore, this kind of marginal, informal old city blocks need to be paid attention to.At the same time, under the circumstance that the epidemic affects life for a long time, it is urgent to return to the living environment and the guarantee of the quality of life. Based on the healthy city theory proposed by the World Health Organization, we should reexamine the reconstruction of the old blocks from the perspective of public safety and health, and put forward planning suggestions that need to be strengthened and improved.

\section{Construction of the evaluation index system for healthy blocks}

\subsection{Evaluation objects and methods}

\subsubsection{Evaluation objects}

This article is based on the perspective of healthy city, from the space form, road traffic, land use, green space and open space, public facilities, population physical and mental health six aspects, including physical and mental health is the most important, because the characteristics not only reflect block residents physical material health, but also reflects the mental health of block population. 


\subsubsection{Evaluation method}

(1) Evaluation method selection

This study compiled 202 related documents on the evaluation of "block index system", and the literature was visualized through the CNIK client.According to the number and analysis of the evaluation methods developed by domestic and foreign index systems, the Delphi method and the hierarchical analysis method or the combined methods are more applied.Based on the content and characteristics of the health community evaluation index system,Delphi and hierarchical analysis were used to study the construction of evaluation index system and evaluation index empowerment synthetically in this study[16][17][18][19][20][21].

(2) Introduction of the evaluation methods

(1) Delphi Method

The Delphi method is mainly a qualitative research method, judged by using the expert's own knowledge, experience and subjective knowledge, which is highly operable[22].In principle, the experts to consult should have the relative authority in relevant research fields and some understanding of the content of evaluation indicators, the number of experts is generally about 10 is the most suitable for[23] .The health community evaluation index system based on this paper lacks mature indicators and practical experience, so it is appropriate to adopt the Delphi method in the establishment of the healthy community evaluation index system[24].

(2) Analytic Hierarchy Process (AHP)

AHP is hierarchical analysis and is a multi-goal decision approach proposed by T.L.Saayt professor of American transport surveyologists, which combines qualitative with quantitative analysis.In recent years, hierarchical analysis has been increasingly applied in various domain[25].The method mainly has the following steps:

a.Establish a hierarchical analysis structure model

Analyze and evaluate the relationship between elements in the system and establish hierarchical hierarchy.The target layer, scheme layer and criterion layer are determined successively, then the relative importance of each level in the hierarchy model is qualitatively judged and quantitatively expressed, then the weight of each level is calculated by mathematical method, and finally evaluate accordingly and choose the optimal scheme.

b.Constructing the judgment matrix

The judgment matrix is $A$, and the corresponding element is aij.aij represents the relative importance of element $\mathrm{i}$ to $\mathrm{j}$, a value based on qualitative judgment.

c.Concordance test

If $C R<0.1$, the judgment matrix $B$ has a satisfactory consistency;

If $C R>0.1$, the judgment matrix $B$ does not have satisfactory consistency, it needs to be rebuilt until satisfactory.

\subsection{Establish an updated quality index system of old blocks under the health perspective}

\subsubsection{Hierarchy model construction}

Reasonable index system is the key to ensure the accuracy of the analysis.Based on frequency statistics, analysis and Delphi method, this paper summarizes the existing evaluation indicators of relevant national standards, domestic and foreign healthy cities and related blocks, and combines with expert 
suggestions.In addition. We also conduct research on some old blocks, and then analyze the impact factors affecting the renewal of old blocks and establish the quality evaluation index system of old blocks update combined with the questionnaire survey results.

\subsubsection{Selection of evaluation indicators}

\section{(1) Construction of the evaluation index structure}

Based on the research content, direction, and purpose.Identify the health block update quality evaluation as the total goal, for the target layer A, using hierarchical analysis combined with the nature of the evaluation indicators, and form the final health block quality evaluation index structure model, mainly divided into three levels, respectively the target layer A, criterion B and C as shown in Fig1:

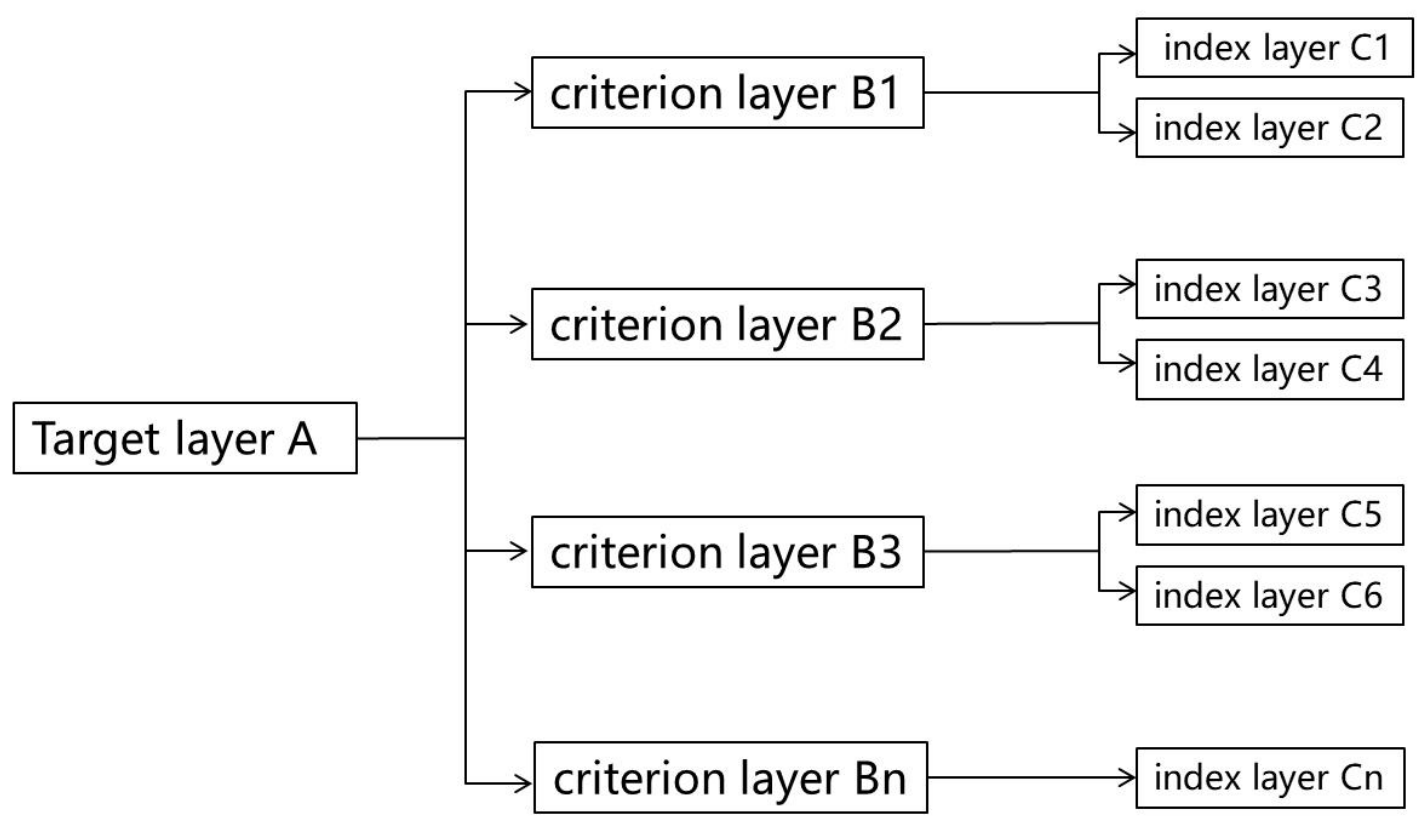

Figure 1. Evaluation index structure model

(2) Determine and establish the evaluation index system

The research content and purpose of domestic and foreign literature review, primary indicators and expert opinions, combined with the structure model of evaluation indicators, is based on the analysis of healthy community evaluation indicators. The health community evaluation index system identified and constructed in this study includes a target level for health evaluation; six standard levels, for health management, health space and healthy transportation; 32 index levels for community property service, community medical facilities, community water environment quality, community greening, physical and mental health, community health services and community safety protection, as shown in Table 1.

Table 1. Update the quality evaluation index system table of healthy blocks 


\begin{tabular}{|c|c|c|}
\hline A: target layer & The B: criterion layer & C: index layer \\
\hline \multirow{26}{*}{$\begin{array}{l}\text { Update quality } \\
\text { evaluation of old } \\
\text { blocks from the } \\
\text { perspective of } A \text { : } \\
\text { healthy city }\end{array}$} & \multirow{3}{*}{ B1: Public Facilities } & C1: facility type \\
\hline & & C2: facility scale \\
\hline & & C3: facility distribution \\
\hline & \multirow{3}{*}{$\begin{array}{l}\text { B2: green space and open } \\
\text { space }\end{array}$} & C4: space scale \\
\hline & & C5: spatial distribution \\
\hline & & C6: plant configuration \\
\hline & \multirow{3}{*}{ B3: land Use } & C7: land type \\
\hline & & The C8: uses the intensity \\
\hline & & C9: mix degree \\
\hline & \multirow{2}{*}{ B4: Road Traffic } & C10: Mobile Traffic \\
\hline & & C11: Slow traffic \\
\hline & \multirow{3}{*}{ B5: spatial morphology } & C12: architectural style \\
\hline & & C13: street form \\
\hline & & C14: myologic morphology \\
\hline & \multirow{12}{*}{$\begin{array}{l}\text { B6: People's physical and } \\
\text { mental health }\end{array}$} & C15: Block Health Education \\
\hline & & The C16: Block has public \\
\hline & & participation for its residents \\
\hline & & The C17: Block residents are \\
\hline & & physically and mentally \\
\hline & & healthy \\
\hline & & C18: Block Health Services \\
\hline & & C19: Block Resident Fitness \\
\hline & & Sports \\
\hline & & $\begin{array}{l}\text { Sunshine hours in the C20: } \\
\text { block }\end{array}$ \\
\hline & & C21: Block Cultural and Public \\
\hline & & Welfare Activities \\
\hline
\end{tabular}

\section{(3) Establish a weight evaluation system}

From the perspective of a healthy city, the old block updates the quality evaluation indicator system formed, we through query data, questionnaire results and combined with the way of experts to give each factor weight, in the form of the table after each influence factors to judge their importance, in order to build the judgment matrix between pairwise factors.After solving the relative weight of each factor, it can be calculated with the maximum feature root of the matrix. According to the calculation results, the consistency of the matrix is judged to ensure the rationality of the relative weight of the factors. The judgment matrix derived from the above process is shown in the table 2.

Table 2. Qualitatively judge the relative weight of each factor 


\begin{tabular}{|c|c|c|c|c|c|c|c|}
\hline $\begin{array}{c}\text { Relative } \\
\text { weight }\end{array}$ & B1 & B2 & B3 & B4 & B5 & B6 & Wi \\
\hline B1 & 1 & $1 / 2$ & 1 & 1 & 1 & 1 & 0.794 \\
\hline B2 & 2 & 1 & 2 & 2 & 2 & 1 & 1.587 \\
\hline B3 & 1 & $1 / 2$ & 1 & 1 & 1 & 1 & 0.794 \\
\hline B4 & 1 & $1 / 2$ & 1 & 1 & 1 & 1 & 0.794 \\
\hline B5 & 1 & $1 / 2$ & 1 & 1 & 1 & 1 & 0.794 \\
\hline B6 & 2 & 1 & 2 & 2 & 2 & 1 & 1.587 \\
\hline
\end{tabular}

Matlab calculates the index weight Wi. in Table 2.2Its maximum eigenvalue is 1.587 , the consistency test result $\mathrm{Cl}$ is 0 , the consistency ratio $\mathrm{CR}$ is 0 , all less than 0.1 . The easy knowledge judgment matrix has consistency, you can continue the analysis and calculation.

Use Matlab again to calculate the factor weight coefficient of the index layer again, and finally get the comprehensive weight of each and the factor proportion structure. The calculation results are shown in the table 3.

Table 3. Update the weight table of quality evaluation index for healthy blocks 


\begin{tabular}{|c|c|c|}
\hline Indicator layer $\mathrm{C}$ & $\begin{array}{l}\text { The index layer C } \\
\text { represents the } \\
\text { weight of the } \\
\text { corresponding } \\
\text { criterion layer B }\end{array}$ & $\begin{array}{c}\text { The index layer C occupies } \\
\text { the weight of the target } \\
\text { layer } A\end{array}$ \\
\hline C1: facility type & 0.540 & 0.0675 \\
\hline C2: facility scale & 0.300 & 0.0375 \\
\hline C3: facility distribution & 0.163 & 0.0204 \\
\hline C4: space scale & 0.600 & 0.150 \\
\hline C5: spatial distribution & 0.200 & 0.0365 \\
\hline C6: plant configuration & 0.163 & 0.020 \\
\hline C7: land type & 0.540 & 0.068 \\
\hline The C8: uses the intensity & 0.300 & 0.038 \\
\hline C9: mix degree & 0.164 & 0.021 \\
\hline C10: Mobile Traffic & 0.164 & 0.021 \\
\hline C11: Slow traffic & 0.448 & 0.056 \\
\hline C12: architectural style & 0.310 & 0.039 \\
\hline C13: street form & 0.493 & 0.062 \\
\hline C14: myologic morphology & 0.196 & 0.025 \\
\hline C15: Block Health Education & 0.283 & 0.035 \\
\hline $\begin{array}{l}\text { The C16: Block has public } \\
\text { participation for its residents }\end{array}$ & 0.106 & 0.013 \\
\hline $\begin{array}{l}\text { The C17: Block residents are } \\
\text { physically and mentally healthy }\end{array}$ & 0.388 & 0.097 \\
\hline C18: Block Health Services & 0.231 & 0.058 \\
\hline C19: Block Resident Fitness & 0.164 & 0.041 \\
\hline Sports & & \\
\hline Sunshine hours in the C20: block & 0.124 & 0.031 \\
\hline C21: Block Cultural and Public & 0.094 & 0.023 \\
\hline
\end{tabular}

It can be seen from table 2 that the weight order of the impact on the renewal quality of old blocks from the perspective of healthy city is as follows: healthy body and mind $(B 6)=$ green space and open space (B2) $>$ public facilities $(B 2)=$ land use $(B 3)=$ road traffic $(B 1)=$ spatial form (B5) = road traffic (B4), that means people's physical and mental health, green space and open space have the greatest impact on the renewal quality of old blocks, Public facilities, land use and spatial form take the second place. It can be seen that in today's social background, people in old neighborhoods pay more attention to mental health.

It can be seen from table 3 that the weight of space scale and physical and mental health of residents in the block is large, which are 0.150 and 0.097 respectively, which shows that the people in the old block very much hope to have a large-scale green space and open space for activities and social communication, and they are very eager to improve the spiritual level. Therefore, in the renewal of old blocks, we need to create more communication space by means of spatial intervention, so as to increase more social connections among the people in old blocks. 


\section{Evaluation of renewal quality of Xichang Block in Changsha}

\subsection{Block introduction}

Xichang Block in Changsha City, Hunan Province has been located in the city center since ancient times. The existing buildings were mainly built in the 1950s. Xichang street is one of the eight famous oldest streets in old Changsha. Today, the inside and outside of the block are quite different. Beside Xichang Block, Wanda Square and Wuyi square are the core business districts of changsha city, which are bright and well-built; The interior of the block is old and backward. Xichang street is the main distribution center of agricultural products and seafood in Changsha. Due to serious health problems and block function transformation, it is urgent to carry out systematic plans in the critical period of health regulation after the large seafood market is closed.

\subsection{Evaluation before update}

\subsubsection{Current situation evaluation}

Based on the renewal quality evaluation system and index weight table of old blocks from the perspective of healthy city constructed above, score statistics and calculation are carried out for each index in index layer $C$ to obtain the weighted score of each index, the score of criterion layer $B$ and the final score, as shown in Table 4. It is calculated that the total score of the current situation evaluation of Xichang Block is 31.92, which is at a low level.

Table 4. current situation evaluation of Xichang Block 


\begin{tabular}{|c|c|c|c|c|c|c|}
\hline Indicator layer C & $\begin{array}{l}\text { Index } \\
\text { layer C } \\
\text { evaluati } \\
\text { on index } \\
\text { score }\end{array}$ & $\begin{array}{l}\text { The index } \\
\text { layer C } \\
\text { represents } \\
\text { the weight of } \\
\text { the } \\
\text { correspondin } \\
\text { g criterion } \\
\text { layer B }\end{array}$ & score & $\begin{array}{l}\text { Criteri } \\
\text { a } \\
\text { layer } \\
\text { B } \\
\text { score }\end{array}$ & $\begin{array}{l}\text { The index } \\
\text { layer C } \\
\text { occupies } \\
\text { the } \\
\text { weight of } \\
\text { the target } \\
\text { layer A }\end{array}$ & $\begin{array}{l}\text { scor } \\
\text { e }\end{array}$ \\
\hline C1: facility type & 11.5 & 0.540 & 6.21 & \multirow{3}{*}{14.56} & 0.0675 & 0.78 \\
\hline C2: facility scale & 16.3 & 0.300 & 4.89 & & 0.0375 & 0.61 \\
\hline C3: facility distribution & 21.2 & 0.163 & 3.46 & & 0.0204 & 0.43 \\
\hline C4: space scale & 6.2 & 0.600 & 3.72 & \multirow{3}{*}{12.12} & 0.150 & 0.93 \\
\hline C5: spatial distribution & 36.7 & 0.200 & 7.34 & & 0.0375 & 1.38 \\
\hline C6: plant configuration & 5.3 & 0.200 & 1.06 & & 0.0375 & 0.20 \\
\hline C7: land type & 65.2 & 0.163 & 10.63 & \multirow{3}{*}{59.93} & 0.020 & 1.30 \\
\hline $\begin{array}{l}\text { The C8: uses the } \\
\text { intensity }\end{array}$ & 56.8 & 0.540 & 30.67 & & 0.068 & 3.86 \\
\hline C9: mix degree & 62.1 & 0.300 & 18.63 & & 0.038 & 2.36 \\
\hline C10: Mobile Traffic & 31.5 & 0.164 & 5.17 & \multirow{2}{*}{40.69} & 0.021 & 0.66 \\
\hline C11: Slow traffic & 79.3 & 0.448 & 34.63 & & 0.056 & 4.33 \\
\hline C12: architectural style & 25.2 & 0.540 & 13.61 & \multirow{4}{*}{37.48} & 0.0675 & 1.70 \\
\hline C13: street form & 41.1 & 0.300 & 12.33 & & 0.0375 & 1.54 \\
\hline $\begin{array}{l}\text { C14: myologic } \\
\text { morphology }\end{array}$ & 70.8 & 0.163 & 11.54 & & 0.0204 & 1.44 \\
\hline $\begin{array}{l}\text { C15: Block Health } \\
\text { Education }\end{array}$ & 28.5 & 0.283 & 16.56 & & 0.035 & 2.05 \\
\hline $\begin{array}{l}\text { The } \mathrm{C} 16 \text { : Block has } \\
\text { public participation for } \\
\text { its residents }\end{array}$ & 16.9 & 0.106 & 1.79 & \multirow{7}{*}{33.64} & 0.013 & 0.22 \\
\hline $\begin{array}{l}\text { The C17: Block } \\
\text { residents are } \\
\text { physically and }\end{array}$ & 12.5 & 0.388 & 12.61 & & 0.097 & 3.15 \\
\hline $\begin{array}{l}\text { C18: Block Health } \\
\text { Services }\end{array}$ & 57.9 & 0.231 & 13.37 & & 0.058 & 3.36 \\
\hline $\begin{array}{l}\text { C19: Block Resident } \\
\text { Fitness Sports }\end{array}$ & 19.3 & 0.164 & 3.17 & & 0.041 & 0.79 \\
\hline $\begin{array}{l}\text { Sunshine hours in the } \\
\text { C20: block }\end{array}$ & 3.1 & 0.124 & 0.38 & & 0.031 & 0.10 \\
\hline $\begin{array}{l}\text { C21: Block Cultural } \\
\text { and Public Welfare } \\
\text { Activities }\end{array}$ & 21.4 & 0.094 & 2.95 & & 0.023 & 0.72 \\
\hline Total score & & & & & & $\begin{array}{l}31.9 \\
2\end{array}$ \\
\hline
\end{tabular}




\subsubsection{Analysis of current situation evaluation results}

The evaluation results of the current situation of Xichang Block can be analyzed from the score of the criterion layer and the score of the index layer. The main deficiencies are in public facilities, green space and open space. Specifically, we need to pay attention to the type and scale of public facilities, the scale of green space and open space and plant configuration, residents' physical and mental health and block sunshine coefficient.

In terms of public facilities, the score is 14.56, which is at a poor level as a whole. The two indicators in the indicator layer have low scores for facility type and facility scale, showing the characteristics of insufficient facility type, incomplete coverage and small scale.

In terms of green space and open space, the score is 12.12, which is at a poor level as a whole. The index layer includes spatial scale, spatial distribution and plant configuration. The scores of space scale and plant configuration are low, showing the characteristics of small-scale green space and open space occupied by sundries, wide but uneven distribution, single plant configuration and lack of characteristics and localization.

In terms of land use, the score is 59.93, which is at a good level as a whole. The scores of land type, use intensity and mixing degree of the three indicators in the index layer are higher than those of the first two criteria layers, showing the characteristics of rich land use types but unbalanced structure, high building density but low plot ratio and high mixing degree of land use.

In terms of road traffic, the score is 40.69 , which is at the general level as a whole. The indicator layer includes motor traffic and chronic traffic. Among them, slow traffic is prominent and motor traffic is insufficient, showing the characteristics of strong continuity of chronic footpath, wide coverage and serious motor traffic congestion.

In terms of spatial form, the score is 37.48 , which is at a poor level as a whole. The index layer includes architectural style, street form and texture form. Among them, the architectural style score is low, the street shape reaches the general level, and the texture shape is good, showing the characteristics of poor preservation of traditional buildings, lack of repair of old buildings, winding street shape, aspect ratio to meet people's sense of experience, good preservation of urban traditional texture and strong identifiability.

In terms of physical and mental health, the score is 33.64, which is at a poor level as a whole. The indicator layer includes block health education, block residents' public participation, block residents' physical and mental health, block health services, block residents' fitness activities, block sunshine hours, block culture and public welfare activities. Among them, the scores of public participation, physical and mental health, fitness activities, sunshine hours, culture and public welfare activities of block residents are low, showing the characteristics that residents do not care about the block and lack of attention, excessive living density and poor sanitary environment, no time for fitness and no space for fitness, and the sunshine time of $50 \%$ of the block in cold days is less than 1 hour.

\subsection{Ways of optimization analysis}

Based on the current situation evaluation results, the targeted planning optimization of Xichang Block is carried out, focusing on the type and scale of public facilities with the lowest score, the scale of green space and open space and plant configuration, residents' physical and mental health and block sunshine coefficient, and the optimization path research is carried out in order to make up for the shortcomings and finally realize the dual improvement of the built environment and human health of the block. 


\subsubsection{Use the existing vacant buildings to improve the allocation of public facilities}

According to the evaluation results of the current situation of Xichang street, public facilities are one of the lowest standard floors. As Xichang street has been built for a long time, the land use right is complex and the transformation is difficult. At the same time, there are a large number of residential buildings underground. Considering the shortage of renting existing vacant buildings for public facilities, so as to achieve the goal of full category and full coverage.

\subsubsection{Strengthen green space and open space cleaning and landscape transformation}

Limited by the fact that it is difficult to dismantle and change the built buildings, it is difficult to expand the existing space. During the implementation, we should strengthen the management of the neighborhood committee of Xichang Block, clean up the existing green space and open space, in order to achieve the maximum utilization, transform the landscape, enrich the plant configuration, and insert local unique plants to strengthen the greening culture. In addition, it is recommended that residents conduct three-dimensional greening of residential buildings on the balcony to improve the experience of green space and open space from the three-dimensional dimension.

\subsubsection{Using pedestrian system and surrounding squares to advocate residents' movement}

The pedestrian network of Xichang Block is densely and widely distributed, and there are many large squares around. It is suggested to contact and guide through planning means, build a complete sports network, strengthen sports health education and publicity, and advocate residents to strengthen sports.

\subsubsection{Renovation, demolition and reconstruction of buildings to ensure sunshine level}

The poor sunshine level in Xichang street has a great impact on Residents' health. In combination with the demand of widening roads in terms of motor traffic, the buildings along the street shall be reconstructed by road occupation, demolition, renovation of outward protruding structures, reconstruction of overhanging balconies, etc., so as to solve the problem of insufficient sunshine in the road system. The dark and humid cluster buildings inside are combed to increase the sunshine time of each building.

\subsection{Re-evaluation after update}

After the planning renewal and targeted optimization of Xichang Block, the scheme is updated and then evaluated, and the current situation of the standard is evaluated to obtain the renewal quality level of the planning scheme, as shown in table 5. According to the calculation, the total score of the renewal quality evaluation of Xichang Block is 52.52, which is at the medium level, which is 23.71 points higher than that before the renewal. Although there is still a certain gap from the new block, the living environment and residents' health have been significantly improved.

Table 5. comparison of renewal quality of Xichang Block 


\begin{tabular}{|c|c|c|c|c|c|}
\hline Indicator layer C & $\begin{array}{l}\text { C } \\
\text { evaluation } \\
\text { index } \\
\text { score }\end{array}$ & $\begin{array}{l}\text { Update after } \\
\text { the index } \\
\text { layer C } \\
\text { evaluation } \\
\text { index score }\end{array}$ & $\begin{array}{l}\text { Updat } \\
\text { e the } \\
\text { pre- } \\
\text { score }\end{array}$ & $\begin{array}{l}\text { Upda } \\
\text { ted } \\
\text { score }\end{array}$ & $\begin{array}{l}\text { Rate of } \\
\text { Change } \\
\text { (after } \\
\text { update / } \\
\text { before } \\
\text { update) } \\
\end{array}$ \\
\hline C1: facility type & 11.5 & 45.2 & 0.78 & 3.05 & $393.04 \%$ \\
\hline C2: facility scale & 16.3 & 44.1 & 0.61 & 1.65 & $270.55 \%$ \\
\hline C3: facility distribution & 21.2 & 65.2 & 0.43 & 1.33 & $307.55 \%$ \\
\hline C4: space scale & 6.2 & 34.2 & 0.93 & 5.13 & $551.61 \%$ \\
\hline C5: spatial distribution & 36.7 & 57.8 & 1.38 & 2.17 & $157.49 \%$ \\
\hline C6: plant configuration & 5.3 & 86.5 & 0.20 & 3.24 & $1632.08 \%$ \\
\hline C7: land type & 65.2 & 67.3 & 1.30 & 1.35 & $103.22 \%$ \\
\hline $\begin{array}{l}\text { The C8: uses the } \\
\text { intensity }\end{array}$ & 56.8 & 65.2 & 3.86 & 4.43 & $114.79 \%$ \\
\hline C9: mix degree & 62.1 & 61.4 & 2.36 & 2.33 & $98.87 \%$ \\
\hline C10: Mobile Traffic & 31.5 & 53.2 & 0.66 & 1.12 & $168.89 \%$ \\
\hline C11: Slow traffic & 79.3 & 83.1 & 4.44 & 4.65 & $104.79 \%$ \\
\hline $\begin{array}{l}\text { C12: architectural } \\
\text { style }\end{array}$ & 25.2 & 49.7 & 1.70 & 3.35 & $197.22 \%$ \\
\hline C13: street form & 41.1 & 48.2 & 1.54 & 1.81 & $117.27 \%$ \\
\hline $\begin{array}{l}\text { C14: myologic } \\
\text { morphology }\end{array}$ & 70.8 & 87.6 & 1.44 & 1.79 & $123.73 \%$ \\
\hline $\begin{array}{l}\text { C15: Block Health } \\
\text { Education }\end{array}$ & 28.5 & 45.1 & 1.00 & 1.58 & $158.25 \%$ \\
\hline $\begin{array}{l}\text { The } \mathrm{C} 16 \text { : Block has } \\
\text { public participation for } \\
\text { its residents }\end{array}$ & 16.9 & 25.1 & 0.22 & 0.33 & $148.52 \%$ \\
\hline $\begin{array}{l}\text { The C17: Block } \\
\text { residents are } \\
\text { physically and } \\
\text { mentally healthy }\end{array}$ & 12.5 & 48.2 & 1.21 & 4.68 & $385.60 \%$ \\
\hline $\begin{array}{l}\text { C18: Block Health } \\
\text { Services }\end{array}$ & 57.9 & 65.2 & 3.36 & 3.78 & $112.61 \%$ \\
\hline $\begin{array}{l}\text { C19: Block Resident } \\
\text { Fitness Sports }\end{array}$ & 19.3 & 54.2 & 0.79 & 2.22 & $280.83 \%$ \\
\hline $\begin{array}{l}\text { Sunshine hours in the } \\
\text { C20: block }\end{array}$ & 3.1 & 33.1 & 0.10 & 1.03 & $1067.74 \%$ \\
\hline $\begin{array}{l}\text { C21: Block Cultural } \\
\text { and Public Welfare } \\
\text { Activities }\end{array}$ & 21.4 & 65.3 & 0.49 & 1.50 & $305.14 \%$ \\
\hline Total & & & 28.81 & 52.52 & $182.32 \%$ \\
\hline
\end{tabular}




\section{4. conclusion}

From the perspective of healthy city, the renewal quality of old communities is analyzed by analytic hierarchy process. The analysis results show that old blocks pay most attention to the green space, open space and people's physical and mental health, which also provides a strong basis for the renewal and transformation of old blocks. Renewal measures not only focus on the local material environment, but also consider how to promote the physical and mental health of the people in the block through the transformation of the material environment, so as to make the renewal behavior closer to the needs of the people. This is a combination of "top-down" and "bottom-up" updates.

\section{1 "Humanistic" renewal of built environment}

The absence of "humanism" in space construction and the imperfect evaluation and construction system lead to the fact that the substantive problems of many old blocks have not been effectively solved, and there are many other cases of "mechanically copying". The renewal of old neighborhoods needs to explore the substantive problems of neighborhoods, and make their built environment and the health of residents.

\subsection{Improve the "natural healing" function of the block}

It can be seen from the establishment of the renewal quality evaluation system of old blocks that most people have high demands for green space, which is specifically reflected in the hope of a larger space scale; More sufficient sunshine duration; Better plant configuration. A good built environment is one of the important factors to promote people's physical activities, especially walking activities, and it is also an important entry point for urban planning to actively intervene in people's health[26].Improving the built environment and enhancing the "natural healing" function of old blocks is an effective means of renewal.

\subsection{Neighborhood renewal promotes the "social connection" of neighborhood people}

Many old neighborhoods in China did not pay too much attention to the construction of communication space and rest space because they were built earlier, coupled with the change of the background of the times, many neighborhood relations have changed, and the relationship between people has been gradually broken. Therefore, it is necessary to rebuild the social connection between people by adding positive public space or through some policy intervention of public participation, so as to improve the happiness of neighborhood residents. 


\section{References}

[1] Chen, P. Qian, L. Q. (2020). Practical exploration on micro renewal of "landscape + sponge" in old community -- Nanban Lane renovation project in Shangcheng District, Hangzhou. Chinese garden, 36(S2), pp. $77-80$.

[2] Zeng, D. H. Chen, C. J. and Dong, X. Y. (2018). The impact of urban renewal on the work residence relationship of indigenous residents in old urban areas -- Taking shibati in Chongqing as an example. Urban issues, (02), pp. 98-103.

[3] Sheng, H. T. (2007). Renewal and continuation in the reconstruction of old urban areas -- Taking the reconstruction project of Zhanzhan Road, Wenhua street, Jinghan Avenue as an example. Urban planning, (08), pp. 93-96.

[4] Huang, H. Bert, S. and Jos, V. (2010). Research on the protection and renewal of historical blocks under the concept of Cultural Ecology -- Taking the historical block of Qingdao Road in Wuhan as an example. Planner, 26(05), pp. 61-67.

[5] Biddulph, M. (2010). Sustainable Urban design: An environmental approach, 2nd Edition. Urban Design International, 15(1), pp. 68-70.

[6] Tao, E. (2015). Research on from "economic old district reconstruction" to "social urban renewal" . Urban Development Research, 22(004), pp. 111-116.

[7]Wang, C. H. Li, Z. W. (2019). Takes the renewal and reconstruction of Middle and North China Village in Kunshan City as an example. Modern Urban Studies, (11), pp. 104-112.

[8] Qiu, B. X. (2016). New way of green old urban transformation — to increase effective investment in China. Construction Science and Technology.

[9] Cai, Y. N. Yang, F. S. and Li, D. L. et al. (2017). Content and Countermeasures of "MicroTransformation" in Old Urban Cities. Urban Development Research, 04, pp. 35-40.

[10]Han, Y. F. (2019). On the application of greening habitat improvement in urban block renewal. Chinese garden, 35(S2), pp. 5-9..

[11] Guo, B. Li, Y. and Cao, X. L. (2018). Takes the old urban area of Shaanxi Province as an example. Urban Issues, (7), pp. 70-76. 
[12] Liu, J. W. Hu, W. P. and Xie, F. Y. (2020). Exploration and Practice of —— Based on the Comparative Study of Chengdu, Guangzhou and Shanghai. Urban and Rural Construction, 584(05), pp. 56-59.

[13] Yang, X. D. Zhang, J. Y. (2019). PPP model research of existing building green transformation: Evolutionary game perspective. China Soft Science, 339(03), pp. 188-197.

[14] Li, Z. and Zhang, R. Z. (2019). Explore the market intervention method of micro-reconstruction in old urban areas. Urban Development Research, 26(10), pp. 36-41.

[15] Chen, S. S. Zhai, G. F. Ge, Y. F. and Yang, H. F. (2021). Research on community governance and resilience improvement under infectious disease risk based on QRH concept. International Urban Planning, pp. $1-15$

[16] Fu, L. Zhang, Dong, Y. and Yang, X. (2019). Study on evaluation index system of low carbon community. Environmental protection, 47(15), pp. 39-46.

[17] Cheng, H. Yu, L. (2017). Research on Evaluation of smart community in Qingdao. China management informatization, 20(01), pp. 207-210.

[18] Tan, W. A. and Wang, Z. Z. (2019). Research on environmental quality evaluation system of smart community based on AHP. Journal of Shanghai Second University of technology, 36(03), pp. 188-194..

[19] Zhao, Q. (2012). Research on the integration of urban healthy ecological community evaluation system. Tianjin University.

[20] Liu, Q. (2016). Research on Evaluation and planning of healthy communities. Zhejiang University of technology.

[21] He, Y. Xiao, S. Y. and Pu, J. et al. (2020). Operational house fire risk assessment based on analytic hierarchy process. Value engineering, 39(27), pp. 220-221.

[22] Kong, Y. Cui, X. J. and Li, D. J. (2006). Community health services urgently need to strengthen the prevention and treatment of mental diseases. Journal of PLA health medicine, (04), p. 256.

[23] Hu, Y, H. (2000). Comprehensive evaluation method. Beijing: Science Press.

[24] Zhu, Y. Y. Cao, C. J. Li, J. T. (2015). Construction of healthy community evaluation index system by Delphi method. Chinese Journal of preventive medicine, 16(08), pp. 638-641. 
[25] Wang, L. and Catherine, R. (2016). Healthy urban planning and evaluation: Rise and trend. International urban planning, 31(04), pp. 1-3.

[26]Lu, F. D. and Tan, S. H. (2015). Research on the impact of built environment on physical activity: progress and thinking. International urban planning, 30(02), pp. 62-70. 